\title{
Resenha
}

Concepções e proposições em Psicologia e Educação: a trajetória do Serviço de

Psicologia Escolar do Instituto de Psicologia da Universidade de São Paulo Marcondes, A. M., Lerner, A. B.C, \& Fonseca, P.F. (Orgs.)

São Paulo, SP: Blucher, 2017, 257 p.

\section{SOBRE O QUE HÁ DE POLIITICO NAS PRÁTICAS EM PSICOLOGIA E EDUCAÇÃO}

Lenara Spedo Spagnuolo

DOI: https://doi.org/10.11606/issn. 1981-1624.v23i1p191-198.

$\mathbb{1}$

is do que um livro de comemoração dos 40 anos do Serviço de Psicologia Escolar (SePE) do Instituto de Psicologia da Universidade de São Paulo (IPUSP), essa publicação é a documentação de trabalhos de luta e resistência às violências, à homogeneização e à psicologização dos problemas de aprendizagem.

Ler o livro foi uma experiência no sentido amplo. Nele encontramos concepções clínicas, teóricas e políticas que levam a uma proposição - como diz o professor José Sérgio Fonseca de Carvalho no prefácio, a uma proposição sobre como a universidade se articula com a comunidade por meio da demanda educacional.

O SePE do IPUSP foi, ao longo de seus anos de existência, formado por psicólogas e docentes de diferentes perspectivas e linhas teóricas. Apesar disso, o eixo comum sustentado por todas pode ser formulado a partir da seguinte pergunta: "como exercer uma 
postura crítica frente às demandas e aos encaminhamentos dos educadores à Psicologia?" (p. 20). Essa é uma questão ética que se teceu no interior das discussões ocorridas desde a fundação do Instituto de Psicologia, em 1970.

As autoras reunidas nessa coletânea abordam temas como direitos sociais, inclusão e exclusão escolar, educação especial, formação de psicólogos, queixa escolar, instituições de acolhimento, entre outros tópicos de debate no campo. Essa rica compilação é o testemunho de experiências que se deram em áreas de atuação nas quais a psicologia faz fronteira com a educação. Embora se trate de um livro gostoso de ler dado seu caráter autoral, recheado de cenas e relatos, o rigor conceitual não foi deixado de lado. Pelo contrário, é a partir de experiências vividas no encontro com o outro que as formulações teóricas ganham maior consistência.

O livro tem dezessete artigos que estão divididos em três blocos: "Apresentação", "Fundamentos" e "Perspectivas atuais", nos quais encontram-se trabalhos referentes às interfaces entre educação, saúde e assistência social.

No prefácio, José Sérgio Fonseca de Carvalho ressalta que o modo de trabalho proposto pelo SePE configura uma nova maneira de a universidade se relacionar com as demandas sociais. Ou seja, ao avesso de uma perspectiva semiassistencialista que oferece seus saberes para os extramuros da universidade, o SePE inaugurou uma outra forma de conceber o campo da Psicologia da Educação. Não se trata mais de aplicação de teorias e diagnósticos ao âmbito escolar. O objeto de investigação não é mais somente o escolar, mas as relações e os discursos produzidos pelos sujeitos implicados no contexto educativo. O efeito disso é a abertura de um diálogo entre instituições (as educativas e a universidade) que se lançam em uma tarefa comum.

A apresentação do livro é escrita pelas organizadoras Adriana Marcondes Machado, Ana Beatriz Coutinho Lerner e Paula Fontana Fonseca. Nesse texto, as autoras traçam a história do Serviço de Psicologia Escolar, criado em 1977 diante da necessidade da presença de psicólogos que acompanhassem os estagiários de Psicologia, supervisionando seus trabalhos nas instituições educativas. Passaram-se quarenta anos desde a fundação do SePE, o que tem como consequência a formulação e reformulação de diversas questões a partir das marcas das docentes e psicólogas que passaram por ele. Entretanto, a herança deixada por uma das idealizadoras do SePE, Maria Helena Souza Patto, é a linha comum que atravessa os diversos modos de costurar essa prática: "a problematização da ação da Psicologia no campo da Educação tendo em vista as relações de saber e poder que compõem as instituições sociais" (p. 22). 
O segundo bloco do livro, denominado Fundamentos, foi escrito por docentes que fazem ou fizeram parte da equipe do Serviço de Psicologia Escolar.

No primeiro deles, Adriana Marcondes Machado retoma seu livro Crianças de classe especial: efeitos do encontro entre saúde e educação (1994), no qual narra uma experiência com crianças de classe especial a fim de demonstrar como se teceu um dos modos de trabalho do SePE, a pesquisa intervenção. O ponto central debatido no artigo é a constituição do problema em um trabalho de intervenção. Machado sustenta que o problema deve ser compreendido como uma interrogação que leva a uma experiência sensível que faz o pensamento diferir. A experiência do problema mobiliza o pensamento. Uma experiência que como tal será produzida por uma multiplicidade de singularidades: das crianças, dos pais, das professoras e das psicólogas. Na cena apresentada pela autora, cada sujeito com seu pensamento, suas sensações, ideias e formas de viver pôde compor um diálogo para tornar o que parecia um lugar final, "crianças-deficientes-para-sempre", um lugar de passagem.

Maria Cristina Kupfer resgata um texto de sua autoria intitulado "O que toca a/à psicologia escolar" (1997), que tem como objetivo discutir sobre o trabalho do psicólogo escolar orientado pela psicanálise. Naquele momento, falar da psicanálise na educação era heterodoxia, afirma a autora. Isso porque na década de 1990 ainda não era de fácil aceitação a ideia de que o psicólogo poderia atuar fora das quatro paredes do consultório. Passados vinte anos, Kupfer nos conta como foi o percurso trilhado pelas discussões que abordam a articulação entre psicanálise e educação. De fato, essa conversa expandiu muito e esse modo de atuação deixou de ser heterodoxia. Kupfer afirma ainda que outros parâmetros foram criados de modo que a psicanálise pudesse estar presente na educação sem necessariamente a presença do psicanalista. Como exemplo disso, temos os indicadores clínicos de risco para o desenvolvimento infantil (IRDI), que foram construídos a partir de conceitos psicanalíticos e podem ser atualmente considerados como novos parâmetros do espaço psi no âmbito escolar.

Marilene Proença Rebello de Souza percorre em seu artigo o caminho de formalização das principais questões teóricas e práticas que fundamentaram o trabalho no Serviço de Psicologia Escolar. Desde 1987¹ , o SePE esteve pautado na compreensão de que o fracasso escolar é um produto da escola, portanto, das relações sociais, históricas, políticas e institucionais que a integram. Tal perspectiva supõe um compromisso desse serviço com o excluído (crianças e adolescentes) e com o papel desempenhado pela Psicologia na produção de exclusão através de concepções medicalizantes a respeito da queixa escolar. A autora relembra uma série de produções acadêmicas que sistematizaram as principais questões, os referenciais teórico-metodológicos e o complexo objeto de estudo que constituem o trabalho da psicologia escolar. 
Maria Helena Souza Patto, em "Para uma crítica da razão psicométrica" ", estabelece uma crítica importante que até hoje serve como advertência para os psicólogos em suas práticas - aos exames psicométricos. Patto afirma que a concepção científica que sustenta o fracasso escolar considera a marginalidade social como expressão de deficiências biopsicológicas individuais. Para a autora, essa visão medicalizada das dificuldades de escolarização está calcada em uma naturalização da pobreza pois deixa de lado as relações ideológicas e de poder que estão em jogo. Nesse sentido, a avaliação psicológica de crianças de baixa renda muitas vezes pode significar um laudo que justificará, cedo ou tarde, sua exclusão escolar. Laudos que reduzem as crianças a "coisas portadoras de defeito de funcionamento em algum componente da massa psíquica” (p. 71).

Patto é enfática ao dizer que os exames psicométricos são um recurso poderoso de dominação de classe que se vale da justificação ideológica da desigualdade social. Assim, crianças pobres são cotidianamente tomadas como desajustadas, objetalizadas e excluídas em nome do que a psicológica científica convencionou chamar de fracasso escolar. Porém a autora não encerra o texto em tom pessimista; resgata Paulo Freire para propor a reflexão compartilhada diante desse cenário: "algo fundamental, porém, pode ser feito: dialogar sobre a negação do próprio diálogo" (p. 84).

O terceiro bloco da coletânea, denominado "Perspectivas atuais e interfaces entre educação, saúde e assistência social", compreende a maior parte do livro e foi escrito por psicólogas que trabalham ou trabalharam no SePE, ou em parceria com as psicólogas desse serviço.

O primeiro texto é de Carla Biancha Angelucci. A autora discute o lugar dos direitos sociais para pessoas com diferenças (ou, segundo os documentos históricos, deficiências) funcionais na formação de psicólogos. Para isso, relata sua trajetória profissional de modo a localizar como a deficiência tem sido encarada como entidade que "coisifica as pessoas e faz sumir o humano em nós" (p. 96). Como "professora de deficiência", Angelucci

194 Estilos clin., São Paulo, v. 23, n. 1, jan./abr. 2018, 191-198. 
operou uma desconstrução da invisibilidade que esse tema ocupava. A autora dirá que a aposta na criação de novos possíveis na educação só pode ser sustentada coletivamente. Em seu artigo, Angelucci se desnuda para o leitor: mostra suas marcas e sua caminhada servindo-nos como referência tanto teórica como de militância pelo direito das pessoas com deficiência.

O segundo texto é de Ana Beatriz Coutinho Lerner, Daniele Caitano e Isabel Cavalcanti. Desde 2011, o SePE oferece uma modalidade de estágio aos alunos do curso de Psicologia que consiste no acompanhamento da escolarização de crianças com transtornos psíquicos em processo de inclusão escolar. As autoras apresentam duas cenas que ilustram esse trabalho no intuito de transmitir as possíveis “intervenções no escolar", isto é, intervenções que têm efeitos tanto no aluno que frequenta a escola quanto no campo escolar. A escola, nesse ponto, é tomada como uma rede discursiva que define lugares e saberes sobre os alunos. A partir das intervenções dos acompanhantes escolares podemos perceber que a sustentação de perguntas sobre a criança diferente pode promover na escola uma elaboração de novos caminhos para o desafio da inclusão.

No texto seguinte, Renata Guarido traz uma reflexão excelente para pensarmos sobre o lugar oferecido pela lógica medicalizante às crianças hoje na escola. Se nessa lógica um aluno só se positiva quando aprende e se desqualifica quando não responde ao esperado, então, quais os efeitos do "fracasso escolar", uma vez que no lugar do aluno impõe-se um vazio? $\mathrm{Na}$ melhor das hipóteses, a criança deixa de ser aluna e torna-se paciente a ser tratado pelo médico ou psicólogo. É com muito vigor que Guarido defende o direito de todas as crianças ocuparem seu lugar de aluno de modo a recolocar a potência educativa no laço entre ele e o professor.

Paula Fontana Fonseca, em seu artigo, nos apresenta o Núcleo de Educação Terapêutica (NET) que, desde 2013, é uma das frentes do SePE. Em sua montagem institucional, o NET possui inspiração nas práticas do Lugar de Vida e em Bonneuil, nos quais o enodamento entre o tratar e o educar são possibilitadores de novos arranjos no modo de estar no mundo de algumas crianças com transtornos psíquicos graves. A autora traz o lindo caso de Mathias para nos contar como essa clínica pode acolher o que é particular dos interesses de uma criança. Com Fonseca e Mathias, aprendemos que o imprevisível dos encontros pode causar estranhamento, mas também um movimento de criações e invenções que enlaçam sujeitos.

$\mathrm{Na}$ esteira da linha contínua que une o tratar e o educar, Marise Bastos aborda a alfabetização de crianças com Transtorno do Espectro Autista. A autora defende que a escrita pode ser uma ferramenta terapêutica valiosa para essas crianças que apresentam 
entraves em sua constituição subjetiva. Rompendo com a ideia muito difundida de que só se aprende a escrever depois de falar, Bastos apresenta um caso interessante que nos deixa curiosos sobre como são poderosos os efeitos da escrita no laço social.

Flavia Ranoya, Ligia Paschoal, Denise Bandeira, Prislaine Krodi e Maria Clotilde Magaldi são as autoras do texto que discute o lugar dos psicólogos nas creches/pré-escolas da USP. Diante de um contexto em que a lógica tecnocientífica rege os laços, inclusive educacionais, as autoras propõem um resgate da esfera educativa incluída no ato de cuidar de modo a favorecer a constituição subjetiva dos bebês. Esse resgate tem como premissa compreender a função educativa como aquela transmissora de marcas simbólicas. É por meio de cenas do processo de adaptação de uma criança pequena que as autoras nos convocam a refletir sobre as dificuldades e possibilidades enfrentadas pelo psicólogo na creche no âmbito da promoção da saúde mental.

O plantão institucional é outro tema tratado no livro pelo artigo de Adriana Marcondes e Yara Sayão. É um dispositivo de atendimento oferecido no IPUSP desde 1996, voltado a equipes multiprofissionais que atuam em instituições públicas, nos campos da educação, saúde e assistência social. O serviço é uma das respostas encontradas pelas psicólogas do SePE para proceder em relação às demandas da comunidade: palestras formativas para os professores, avaliação para os alunos, entre outros. É uma outra proposta de intervenção em que, ao se questionar e discutir as práticas existentes e já naturalizadas pela instituição, pode-se sair da repetição e promover novos movimentos em direção à responsabilização coletiva dos profissionais.

Outro dispositivo de atendimento do SePE é a Orientação à Queixa Escolar, tema do artigo escrito por Beatriz de Paula Souza. Também tendo como premissa as práticas antimedicalizantes, visa intervir na rede de relações que constitui o processo de escolarização. Em geral, essa rede é composta pelo aluno, sua família e sua escola. Na contramão da individualização e medicalização da queixa escolar, os profissionais desses serviços trabalham em parceria com esses atores, a partir de uma perspectiva institucional, com a intenção de promover movimento e autonomia à rede. Como efeito desse dispositivo, Souza nos conta da emancipação dos sujeitos envolvidos, que contribui para transformar as condições de produção de fracasso e sofrimento ligados ao âmbito da escolarização.

O texto seguinte é escrito por Yara Sayão para apresentar a supervisão institucional por meio do Plantão Institucional do SePE às equipes dos Serviços de Acolhimento Institucional para Crianças e Adolescentes (Saica) ${ }^{3}$. A autora traça a história atravessada de dificuldades que caracteriza o complexo serviço que é o Saica: entre o público e o privado, a educação, a assistência social e o judiciário, o coletivo e o singular. Os abrigos são permeados por tensões que se apresentam

196 Estilos clin., São Paulo, v. 23, n. 1, jan./abr. 2018, 191-198. 
através da angústia dos profissionais desse serviço que buscam a supervisão. Outra perspectiva de intervenção é o estágio de psicologia nos Saicas, que visa "possibilitar que crianças e adolescentes acolhidos se coloquem como sujeitos de sua própria história, conheçam mais sua trajetória de vida, estabelecendo relações entre vivências, sentimentos e fragmentos de histórias relatadas" (p. 199). A partir de sensíveis relatos dos estagiários, Sayão nos mostra a potência do encontro possível entre a criança ou adolescente e os estagiários.

Marina Massari e Marina Cristina Vicentin discutem os processos de medicalização em ação no campo do serviço de acolhimento. As autoras elegem três analisadores para propor essa reflexão de modo a ilustrar de que maneira ainda persistem as práticas de medicalização na forma do uso indiscriminado de medicação e do "tratamento hospitalocêntrico" (p. 220). Algumas práticas atuais são criticadas pelas autoras pois são desprovidas de articulação em rede e da participação dos diversos profissionais de saúde e assistência social envolvidos no território.

A prática do psicólogo no Saica é o tema central do artigo de Sthefânia Carvalho. A autora relata cenas de experiências vividas no seu encontro com crianças e adolescentes do Saica, que transmitem a potência da intervenção em ato desse profissional. Tal intervenção tem como direção ético-política a produção coletiva de histórias a partir da sustentação de um espaço para a manifestação subjetiva daquele sujeito, "fazendo resistência ao rolo compressor homogeneizante de toda instituição" (p. 236). Assim, mediados pela sensibilidade da autora, entramos em contato com histórias de violência e violações que, quando compartilhadas e vividas junto com o outro, são capazes de colocar a vida em questão e em movimento.

Por fim, no último artigo que integra o livro, Siglia de Sá Leão e Jéssica Oishi abordam o trabalho do psicólogo nas varas de Infância e Juventude. As autoras apresentam dois casos em que, sob o discurso do cuidado e da proteção da criança e do adolescente, têm demandado da psicologia respostas "verdadeiras" e saídas "eficientes" para as situações de violência, sofrimento e desamparo 
vividas por eles. Segundo as autoras, as exigências por classificações e diagnósticos trazem subjacente o princípio da utilidade, que pretende eliminar o problema. Desse modo, diante da tal violência institucional silenciosa, crianças e adolescente são apagados, assim como suas questões a respeito de sua própria história. Será possível resistir a essa lógica? Essa é a pergunta disparada pelas autoras.

O ponto-chave que perpassa o livro é o testemunho sobre a posição do psicólogo diante das demandas sociais, políticas e culturais de nossos tempos. Cada autora, a seu modo, pôde responder a essa inquietante indagação a partir de suas práticas preciosas e teorizações rigorosas. Assim, Concepcões e proposições em psicologia e educaşão ganha vida diante de profundas discussões causadas por experiências vividas pelas autoras ao longo de sua trajetória profissional.

Esta coletânea nos mostra que a reflexão é mais valiosa quando acompanhada da ação e da experiência vivida com o outro. Nesses quarenta anos do SePE, comemora-se mais do que um campo conceitual, de trabalho e de pesquisa que se inscreveu na universidade; comemora-se uma prática com posicionamentos ético e político claros: problematizar, resistir e fazer frente às aplicações tecnicistas e ideológicas da Psicologia dentro do campo educativo.

\section{NOTAS}

1. Em 1987 foi defendida, no IPUSP, a tese de livre-docência da professora Maria Helena Souza Patto intitulada "A produção do fracasso escolar: histórias de submissão e rebeldia”.

2. Artigo originalmente publicado em: PATTO, M. H. S. (2000) Mutações do cativeiro: escritos de psicologia e política. São Paulo: Hacker Editores/Edusp.

3. Essa é a denominaçấo utilizada desde 1990 , com a promulgaçáo do ECA (Estatuto da Criança e do Adolescente), para as Casas de Abrigo que, ainda atualmente, acolhem crianças e adolescentes cuja guarda está provisoriamente com o Estado.

spedolenara@gmail.com

Rua José Augusto Penteado, 156. 01257-010 - São Paulo - SP - Brasil. 